\title{
Grounding Clinical Guidelines in Service Users' Experiences of Endings
}

\begin{abstract}
Purpose. To explore service users' experiences of the process of ending from NHS community personality disorder services.
\end{abstract}

Methodology. Semi-structured interviews were conducted with eight participants recruited from four NHS community Personality Disorder services.

Findings. Three main themes emerged; 'Service users' experiences in the context of Reflective versus Reactive practice', 'Endings held in mind' and 'What next?'

Originality/Value. Further recommendations are provided for practitioners supporting individuals managing endings alongside a 'readiness to end' model which may be used in clinical practice.

Keywords. endings, termination, discharge, clinical guidelines, NICE guidelines, serviceuser experiences, thematic analysis

\section{Acknowledgements}

This paper was written as partial fulfilment of a thesis submitted for DClinPsych at the University of Lincoln in 2009 by the first author. 


\section{Introduction}

The National Institute of Health and Care Excellence (NICE) deemed it necessary to produce clinical guidance on managing endings specifically for individuals with a diagnosis of Borderline Personality Disorder (BPD). The guidelines (NICE, 2009) acknowledge that the end of treatment "may evoke strong emotions and reactions" (1.1.7.1) and recommend that discharge is structured, phased and managed collaboratively with the individual and transitional provider. To our knowledge, BPD is the only presentation that has attracted specific NICE guidelines around endings.

\section{The Importance of Endings}

Endings are considered a prominent, yet predictable feature across many adult-life crises (Sheehy, 1977). They are embedded within expected lifespan experiences such as relationship dissolution (Norona et al., 2017) and grief (Kubler-Ross, 2009) and are commonly discussed within the literature.

Endings are universally significant as they represent a point of change in an individual's life. Examples may include observable changes in an individual's circumstances (e.g. family structure, job, relationship status); however, an ending can also stimulate hidden changes in an individual's perception, perceived responsibilities and sense of stability. For most people, change is welcomed and marks a point of transition and growth (Quintana, 1993), whereas for others, the changes brought about by endings may be destabilising; the unconscious transition does not occur, and instead the ending evokes a plethora of defensive grief reactions (Mann, 1973). The symbolism of ending, the inherent change and the attached individual meaning, suggests ending is an important process for most. With the understanding that endings are universally significant, the exclusivity of endings guidelines seems somewhat unfounded.

Within mental health care services endings are widely considered to be an important phase of therapy for both service users (authors, 2018) and therapists (Råbu et al., 2013) across a wide range of clinical areas and therapy modalities and often elicit a complex emotive response (Wachtel, 2002).

Endings may be particularly important for individuals with a diagnosis of Borderline Personality Disorder (BPD) and consequently the staff supporting individuals accessing services for the following reasons. Firstly, according to the DSM-5 (American Psychiatric Association, 2013) a personality disorder is defined as a way of thinking, feeling and 
behaving that deviates from the individual's cultural expectations and causes them distress or problems in functioning over time. The challenges and distress an individual with BPD experiences relate specifically to their difficulties with self (identity and self-direction) and interpersonal (empathy and intimacy) functioning. Further explained, those with a BPD diagnosis may struggle to empathise with others and to effectively regulate their emotions and they will often attempt to avoid real or imagined abandonment. Considering these key features of BPD, in particular the fear of abandonment, it can be anticipated that the ending of an interpersonal relationship with a healthcare professional may be a difficult and potentially destabilising experience. These anticipated difficulties are acknowledged within the management and support provided to individuals with PD (Bateman and Fonagy, 2000) and are explicitly outlined in practitioner guidelines (Wood et al., 2014) and models of therapy used within PD services (Young et al., 2003).

Yet, despite a considerable amount of literature acknowledging the potential challenge of ending therapy with individuals with a BPD diagnosis, there is little guidance offered to staff around how they can best manage and support this phase of therapy. Clearly, there is a clinical rationale for conducting research that supports the development of more thorough guidelines, particularly because staff consistently report anxieties around supporting individuals with a BPD diagnosis, more so than in other populations (Crawford et al., 2010). In particular, staff concerns relate to the increased level of risks that are commonly perceived to be associated with individuals with a BPD diagnosis (The National Institute for Mental Health in England [NIMHE], 2003).

\section{Key Models for Understanding Endings}

Despite limited early acknowledgement of the 'terminal phase' of treatment, endings have become a longstanding topic of interest amongst psychoanalysts (Freud, 1937) and many other theoretical derivatives, e.g., time-limited therapy (Mann, 1973) and attachment theory (Holmes, 2010). As summarised in Delgado and Strawn (2012), theoretical perspectives differ in terms of their conceptualisation of the ending; however, the vast majority concur with the psychoanalytically derived 'termination as loss' model (Quintana, 1993). According to this model, the end of therapy is experienced as a loss, in the sense that what was before is no more. In one half of the model, loss signifies a potential point of crisis in which clinical attention is necessary to work through and manage relapse prevention and risk (Mann, 1973; Strupp and Binder, 1985). Interestingly, however, there is little empirical evidence to support the 'ending as crisis' perspective; the literature suggests that only a small 
proportion of individuals experience an ending to this extreme (Marx and Gelso,1987). More recently there has been a shift towards an 'ending as transformation' model (Quintana, 1993; Maples and Walker, 2014) which asserts that an ending prompts psychological development and growth through processes of internalisation; by which an individual is able to compensate for the internal and external losses of therapy and move forward.

\section{Lack of Empirical Research}

Surprisingly, theoretical interest in the study of endings has had little impact on the development of clinical guidelines. One possible explanation for this transitional deficit from theory into practice may be attributed to the scarcity of empirical research (Roe et al., 2006). The available literature provides a necessary description of the fundamental processes involved in ending therapy (for a summary see Gelso and Woodhouse, 2002); however, there has been little attention given to more in-depth explorations into how endings are actually experienced. In line with the 'ask the client' movement (Elliott, 2010), to effectively manage an ending, we must first develop an understanding of how ending processes are experienced by those in receipt of therapy.

There have been some attempts at understanding service users' experiences (Etherington and Bridges, 2011; Knox et al., 2011; Olivera et al., 2013; Råbu et al., 2013); however, many studies have used survey-based methods (e.g. Fortune et al., 2002) and therefore lack the subjective details of participants' experiences. Surprisingly, some studies have also used indirect methods (staff perspectives) to capture service users' experiences (Quintana and Holahan, 1992; Westmacott and Hunsley, 2017). As demonstrated by Råbu, Binder and Haavind (2013), service users and therapists provide different accounts of the ending experiences and therefore studies employing indirect strategies may not provide an accurate reflection of service users' experiences. In summary, although indicative of the range of experiences, the literature discussed provides only a limited understanding of service users' experiences of ending.

A recent systematic literature review by authors (2018) provides a synthesis of the available published evidence on service users' first account experiences of endings. In summary, peer-reviewed evidence suggests that endings are experienced as an emotionally evocative event that centres on the anticipation of loss. Having control over the ending experience and the service users' sense of responsibility towards the therapist or around the decision to end were also identified as key constructs representative of service users' experiences. However, the available studies were geographically spread and predominately 
from private practice, which limited the review's potential for informing clinical guidelines or practice within time-bounded UK NHS settings. The review concludes that further exploration is required into service users' experiences of endings across different contexts to inform clinical practice guidelines.

\section{Summary and Clinical Relevance}

Endings are an important phase of the therapeutic process and are particularly significant for individuals with a diagnosis of BPD who may struggle with interpersonal functioning and abandonment issues. However, empirical evidence is limited, and guidelines informing practice around the management of endings are sparse. In clinical practice, staff working within services regularly express anxieties around supporting individuals with a BPD diagnosis and have expressed specific concerns around managing risk. Considering endings are also a potentially destabilising experiences for individuals with a BPD diagnosis, there is a clear clinical need and a rationale for conducting research that may inform guidance around how best to manage endings with individual with a BPD diagnosis.

\section{Research Purpose}

Acknowledging the lack of focus on service users' experiences and the highlighted importance of managing endings within PD services, we aimed to explore service users' subjective experiences of endings from NHS community PD services. During the analysis, it became apparent that there were two distinct over-arching themes; service users' experiences of the process of ending and their clinical reactions and responses to the ending. We therefore decided to report the findings in two separate articles. This paper presents three key themes that relate to service users' experiences of the process of ending in practice. This paper may be particularly relevant for staff seeking advice around how to best manage endings in clinical practice. The connected paper (authors, submitted for publication) provides the reader with an understanding of service users' clinical reactions and responses to the ending. Specifically, how endings are experienced as a loss and how an individual's emotional response to loss is managed in part by the role of boundaries.

Developing a deeper understanding of service users' experiences of the ending process could expand the evidence-base, inform clinical guidelines and may improve clinical practice and service effectiveness. 


\section{Methodology}

\section{Ethical Approval}

Ethical approvals were sought and obtained from a local NHS Research Ethics Committee and also from each participating recruitment site. This project followed ethical guidelines from the British Psychological Society (BPS, 2014).

\section{Recruitment}

Participants were recruited from four NHS community PD services. Considered the largest providers nationally (Crawford et al., 2007), NHS community PD services provide a range of support to individuals aged 18 onwards. Support offered to service users typically consists of multi-disciplinary management, care-coordination and a range of evidence-based individual or group interventions. All recruitment services had an inclusion criteria that individuals accessing the service must have a diagnosis or difficulties consistent with a personality disorder diagnosis (including complex needs and risk concerns).

\section{Procedure}

Individuals discharged within the preceding three-months were identified and checked for eligibility by a team clinician. The inclusion criteria required participants to be aged over 18, discharged from the service within the last three months and able to give informed consent. Eligible participants were posted a research invitation pack from the service detailing study information and inviting them to respond or contact the research team for further discussion. All participants had been discharged from the service and so an 'opt -in' method of recruitment was deemed the most ethically appropriate. Respondents were provided with the opportunity to ask questions and discuss the project. Written consent was obtained before the interview was arranged. Participants were given 24 hours from providing consent to reflect on their involvement before the interview took place.

\section{Data Collection}

Participants were interviewed over the telephone by the first author. Interviews were on average 37 minutes in duration and were guided by a semi-structured interview schedule. The schedule contained five set questions and prompts informed by current NICE guidelines (2009) and gaps within the literature (See Appendix A).Beyond these set questions. as 
encouraged by Glaser (1998) open-ended questions were used throughout to facilitate engagement and foster participant exploration of the topic.

\section{Participants}

A total of 103 individuals were invited to participate, 13 (12\%) responded and eight consented to take part. Participants ( 7 females, 1 male) ranged between 23-64 years in age; the average age was 41 years. Seven participants considered themselves White-British and one individual identified as a British-Pakistan female. Time spent in therapy ranged from 3 months to 14 months. Support received by participants reflected the full range of services on offer within community PD services including 1-1 CBT, year-long psychodynamic psychotherapy, community group, structured clinical management, DBT groups, schemainformed groups and skills-based groups. Diagnosis for individual participants was not verified with the service due to confidentiality reasons. however, taking into account the services inclusion criteria, the relative prevalence of BPD (Korzekwa et al.,2008) and participants' own references to BPD within their interviews; the authors make a reasonable assumption that participants involved in this research would meet the diagnostic criteria for BPD.

\section{Analysis}

Interviews were transcribed and analysed using a mixed deductive-inductive hybrid approach (see Table 1), adapted from the thematic analysis framework of Braun and Clarke (2006). A deductive coding framework was developed as a template to guide the deductive process (Crabtree \& Miller, 1999). Codes were derived from the literature, namely the NICE guidelines (2009) and a systematic literature review on service users' subjective experiences on endings (Authors, 2019). A refutational stage (step 4) was added as a process to ensure that the researchers considered contrasting data. It aimed to ensure a balanced perspective of the data and to minimise research bias. This stage was completed by the first author in consultation with the second and third authors. Although Braun and Clarke (2006) provide guidance on how inconsistencies should be managed, the process was not formalised within the original steps of analysis. Having noted the importance of conflicting experiences, we have attempted to formalise this by including the 'refutational' stage as a procedure of analysis. 


\section{Refutational stage of analysis}

Following the process of collating codes (both deductive and inductive) into potential themes (step 3), the first author searched for codes that refuted either the categories of codes or themes developed in the previous step. Where oppositional codes were found, the first considerations were: 1) whether these were proportionate to the original codes or theme, and 2) whether the contrast highlighted a clinically relevant matter in line with the research aims. If the oppositional codes were deemed to be relevant, the original theme was demoted and a new theme created to reflect the refuting codes or themes. This process was checked in supervision by the second and third author.

- insert Table 1 here -

\section{Results}

Three main themes and eight sub-themes emerged from the data and are summarised in table 2 . These themes are discussed below and illustrated by interview extracts.

- insert Table 2 here -

Service Users' Experiences in the Context of Reflective vs. Reactive Practice.

This theme captures service users' contrasting experiences of reflective and reactive clinical practice around the management of endings.

\section{Reflective practice experiences.}

Participants suggested that the process and impact of the ending were in most parts considered and reflected upon by the health professional managing the ending. In particular, there was evidence that suggests participant endings were structured and phased, supported, and planned collaboratively.

For example:

"I guess we all knew it was going to come to an end so they did slowly wean us off the intensity... I think it was good how it was planned out" (Participant 2)

"I think I was well prepared, I think we had drawn the conclusions together that I needed from the year -long therapy."(Participant 4) 
"They looked at options outside of the hospital like charities and things that offer support groups or urm.. different things really, you know like, they just hold, like a community centre." (Participant 6)

There was also evidence to suggest that one service was mindful of the impact of ending therapy and had explicitly acknowledged the process by incorporating a dedicated 'ending session' in their group program.

[The final group session] "That was thinking about endings, that was the theme for that weeks session." (Participant 2)

Impact of reflective practice.

Reflective clinical practice concerning the management of endings was received well and suggests a positive emotional impact on participants, who reported a sense of assurance from the health professionals' approach.

"Yes it did help, the tapering off period because although it ended in October I felt like I have only just fully finished now (March). " (Participant 8).

"It feel good that somebody cared, you know they cared enough to try and find something else for me to do". (Participant 1)

"She was good, I cannot fault her she was really helpful." (Participant 7)

"But, you know he did tell me and you know I understood what was going to happen, and that was just, I thought like, oh right, at least he is not going to leave me adrift in the sea, kind of thing. " (Participant 5)

\section{Reactive practice experiences.}

In contrast, some participants reported experiencing the process of ending as unclear, abrupt and lacking in communication. One understanding is that this perhaps indicates that the management of endings was more reactive towards the stimulus that was the end point of therapy.

"I didn't know what was going on, it was up in the air kind of thing. " (Participant 5)

"I felt it was a rushed ending." (Participant 2) 
"The second time I phoned I still couldn't get through so I left a message of his voice mail for him to get in contact with me, and I never got any reply and then I spoke to a lady called ..... who told me that Mr .... he'd left the practice." (Participant 5)

\section{Impact of reactive practice.}

The reactive approach to the management of endings was experienced as unsupportive and abrupt. The negative impact, associated risks and potential unravelling of therapeutic gain was implied within participant experiences.

"It's just none of us were helped to understand the pain and we have all kind of ran away in our own directions from the pain." (Participant 2)

"We will see you when you next try to kill yourself. That is not what is said obviously but that is how it makes you feel."(Participant 6)

"Like they don't care or that you had wasted 12 months because now you're just going back to the life you had before."(Participant 6)

\section{Endings Held in Mind}

The theme 'endings held in mind' refers to the ever-present topic as experienced by participants throughout therapy. The explicit discussion of ending from the start, mentioning throughout, and the significance of 'marking' the end of therapy collectively highlight the prominence of ending.

\section{Explicit from the start.}

Participants reflected that time-bounded therapy, that has a clear start and end was a significant aid for self-managing the ending experience. The boundaries imposed by service limitations and therapeutic models enabled service users to remain focussed, manage expectations and rationalise their emotional response to ending.

"Well, I think the good thing with this was that I always knew it was a year, so it was very much part of, on the cards from day one. It lasts for a year and that's your lot. They very much make it time bound and so I suppose for the whole time I was doing it, that was on the agenda almost, if you know what I mean." (Participant 4) 
"From the second you start you know when it is you are going to end and although it makes it terrifying and a counting clock, it does make it feels like you're not being dropped, you're not being abandoned." (Participant 8)

\section{Endings - not a taboo topic.}

The sub-theme 'endings-not a taboo topic' captures how endings were an un-avoided and welcomed point of reference throughout therapy. Participants reflected how repeated discussions, although difficult, 'diluted' the impact of ending.

"So yeah we thought about it and talked about it throughout the weeks and months now and again" (Participant 3)

"It was always there so it wasn't a surprise, so it was, actually it was good, it wasn't this taboo topic that's never mentioned."(Participant 4)

"It's like its diluted it as such, but it is still really difficult." (Participant 2)

"I think I would definitely keep the mentioning it part because as much as for me it wasn't something I wanted to hear, I think the way that I am feeling now would have been a lot worse if it wasn't mentioned." (Participant 2)

Marking the ending.

The significance of marking the ending for service users, staff and services became apparent through participant experiences. Participants reported how the end of therapy was marked in various ways such as a shared celebration, gift exchange or through receiving a certificate or therapeutic ending letter. One service marked the ending through a dedicated ending-focussed evaluation session which aimed to provide a reflection space for processing the ending.

\footnotetext{
"Yes, in the group they had a little tea party which was quite nice with the therapists and members which was quite nice as well. In the TC [therapeutic community] there was a celebration, so we had like a meal and then we swapped, because I brought the TC something and they had something for me, so we swapped gifts and then I said thank-you, so yes.” (Participant 3)

"Yes, we all brought in cookies and made a point of it ending." (Participant 8)

"She did this very long, very brilliant kind of long reflection on my therapy for me and gave it to me to read before I went into the last session. " (Participant 4)
} 
"Yes, they gave me a certificate to say that I had completed it." (Participant 1)

"It was done in the group, the final group session where we got together to like for the last meeting. That was thinking about endings, that was the theme for that week's session." (Participant 2).

\section{What Next?}

The final theme 'What Next?' captures the contrast between SU hopes and fears for life after therapy. For some, the 'what next' provoked anxiety and the desire to have a failsafe plan to fill the void left from ending therapy. Others welcomed the ending to either consolidate their learning or be free from the commitment of therapy.

Filling the void.

The sub-theme 'filling the void' highlights participants' anxieties and fears around ending therapy and being left in the "big bad world without backup" (participant 6). In response to the perceived void left by therapy participants stressed the need to have something to fall back on.

"You know there is a lot going on and I think if you have got nothing else it would maybe race around in your mind and make you worse. " (Participant 6)

"Well to be honest with you, I did not like the thought of it because, er I did think I would not have anyone else or someone to talk." (Participant 5)

"I think there should be a follow-on group, something, maybe not as intense but something sort of to ease it down a little bit, just something to fall back on." (Participant 1)

\section{A welcomed break from therapy.}

In contrast, other participants welcomed the break from therapy to either consolidate and apply their newly adopted learning and skills, or to be free from the commitment of therapy.

"I need to take a bit of time and take what I have learnt in DBT to actually happen before I can move on. Which is a bit difficult because it feels like I am not doing anything which is not true, but it feels that way... I am quite happy to let it sit for a bit before I pursue my next path of recovery." (Participant 8)" 
"I felt I was just ready to move on, and put stuff behind me... I wanted a break from therapy and a break from everything." (Participant 3)

"I actually think I kind of thought it's nice to not have that commitment, kind of be a bit free from that." (Participant 4)

For some participants the appeal of ending therapy seemed to be related to their sense of achievement or progress in therapy;

"It was quite a sense of achievement I have done this and gained a lot from it." (Participant 4)

"I am not fully recovered, or fully functional for work or social but I don't hurt myself or destroy my relationships the way I used too, which is a massive difference." (Participant 8).

For one individual, therapeutic gain was intrinsically linked to a pivotal moment around taking personal responsibility;

"My life had just got to the point where I was like, I am sick of this I need it to get better and I have to do something to make it change." (Participant 8)

\section{Discussion}

This study aimed to explore service users' experiences of the process of ending from NHS community PD services. Overall the findings highlight the importance of adopting a reflective pro-active approach to the management of endings and we note the positive impact that this had on service users' experiences. In contrast, when endings are seemingly reacted to and not carefully considered, service users reported how this negatively affected their experiences. Results suggested that weaving discussions about endings throughout therapy from start to end was also an important process within participants' experiences of ending. Likewise, the transition into life beyond therapy was highlighted as a pivotal point of reflection within the ending process. Collectively, service users' first account experiences of endings provide a qualitative understanding of the processes of ending.

\section{Reflective vs Reactive}


The positive responses of service users' in receipt of reflective practice highlights the importance of having effective management strategies that specifically ensure the ending processes are considered and prepared for. The findings are consistent with the current NICE guidelines (2009); however, the contrasts between service users' experiences indicate variation in how endings are managed in practice.

One possible explanation for the variation in service users' experiences could be the way clinical guidelines are perceived and utilised by the health professionals. Although NICE guidelines are often considered a rigid prescription for practice (Court et al., 2016), they are often not adhered to (Prytys et al., 2011). Research investigating non-compliance is limited (Berry and Haddock, 2008), however, two barriers to implementing the guidelines include organisational factors (e.g. lack of resources, time and training) (Ince et al., 2016) and unclear or ambiguous recommendations (Lugtenberg et al., 2009). Certainly, the current guidelines for endings (NICE, 2009) lack empirical support and offer vague direction as to how health professionals should implement the recommendations. In summary, non-compliance and variations in how ending guidelines are accessed and interpreted may in part explain the contrasts between participants' experiences of ending.

Also referred to as the research-practice gap (Kristensen et al., 2016), this discussion highlights a particularly salient point for the current and future research that perhaps assumes that writing better guidelines will improve patient care. As illustrated, service users' experiences of endings vary and are somewhat contingent on staff adherence and perceived value around the utility of clinical guidelines. Accordingly, it may be more feasible to redirect research effort and intervention towards organisational factors (e.g. improvement strategies; see Ince et al., 2016).

Findings from the current study provide evidence suggesting that services are adopting their own practices around the management of endings in therapy (e.g. a dedicated ending session). Arguably, the practices reported may reflect how services have interpreted the current NICE recommendations; however, there is evidence within the field that services are developing in-service recommendations to support how they manage endings (e.g. Keane et al., 2015). The use of practice-based evidence is considered a valuable strategy for enhancing the local provision of care (Holmqvist et al., 2015); however, it raises a question around the sufficiency of the current NICE guidelines. Arguably, the lack of detail and specificity within the guidelines may encourage practitioners to reflect on their practice and prevent the recommendations from being adopted as a prohibitive instruction (Mollon, 2009). The developments in practice-based evidence suggest that there are sufficient gaps within the 
literature and current recommendations that warrant further exploration. On this basis, we encourage health professionals to use the NICE guidelines alongside research and practicebased evidence to support service users throughout the process of ending.

\section{Endings Held in Mind}

The research highlights how endings were 'held in mind' from the start and throughout the entirety of therapy. The repeated mentioning and discussion of the anticipated ending may have functioned to gradually and repeatedly expose an individual to the loss of therapy and reduce the emotional impact of ending. Particularly within group-therapy settings exposure to the emotional responses to loss is intrinsic. Further explained, previous experiences of loss are said to influence how an individual may respond to current separation and loss (Firestein, 2001; Holmes, 1997). There has, however, been little consideration for the losses that occur within therapy. Indeed, separation and loss are embedded within the processes of psychotherapy (Holmes, 2010); which is often peppered with repeated separations such as the ending of each therapy session, breaks in therapy and the occasional therapeutic rupture. In a similar vein to how mentioning the topic 'dilutes' the impact of ending, the repetition of these smaller losses throughout therapy may expose an individual to the emotional aspects of endings. Particularly within open-group therapy settings, service users regularly experience group members coming and going. These subtle losses may evoke undesirable responses; however, when experienced within a supportive therapeutic environment, a loss can be processed, and emotional distress can be contained. As suggested in Sroufe's (2005) 'transactional model of attachment', a loss can be managed successfully through a supportive context. In summary, exposure to loss during therapy creates a relearning experience for the individual around how to end well.

\section{What Next?}

The theme 'What Next?' highlights the contrasting ways in which service users respond differently to the prospect of life after therapy. Consistent with Quintana's (1993) 'ending as transformation' model, some service users felt empowered and welcomed the transition. In contrast, other service users expressed anxiety around ending and were more resistive, although not ever to the extent of crisis as indicated in the theoretical literature (Quintana, 1993).

The differences in service users' responses towards the anticipated endpoint can perhaps be understood relative to an individuals' readiness to end therapy. Drawing upon the 
stages of change model (Prochaska and DiClemente,1983) we speculate that individuals who sought to 'fill the void' of therapy would likely be positioned at the 'pre-contemplation' stage and considered not ready to end. In contrast, individuals who welcomed the break from therapy would sit at the 'preparation' stage. The dilemma here is that the boundaries of timelimited therapy mean therapy will end regardless, and therefore, an individual may end despite not feeling entirely ready. This ambivalence is likely to evoke fear in response to the loss of ending therapy (Authors, submitted for publication). The task of therapists here is to, 1) establish where an individual is at in terms of the readiness to end using the adapted stages of change model, and, 2) support the individual to move through the stages towards ending effectively.

Factors that impact an individuals' 'readiness to end' and strategies for supporting the transition of change can be elicited from the broader literature informing transition throughout the original stages of change model (Prochaska et al., 2013). However, the current findings suggest that feeling a sense of achievement (goal-attainment), having acceptance around the current stage of recovery and taking responsibility for progress are key enablers that supported individuals to move towards accepting the ending of therapy.

A final point of discussion reflects how some service users viewed the ending of therapy as a break within their 'path of recovery', rather than an absolute endpoint. This finding is consistent with the literature that demonstrates re-referral rates to be high (Cairns, 2014) but is also in keeping with the perceived clinical practice of health professionals who reportedly leave the therapy 'door open' (authors, 2018). Conceptualising the ending in this temporary way may reduce the permanency of the change process and therefore alter how an individual perceives, experiences and responds to the ending of therapy. Arguably, viewing the ending as an interrupt enables an internalised connection to remain beyond therapy, that perhaps reduces the emotional impact of ending and diffuses the potential for ending 'crisis' (Mann, 1973; Quintana, 1993).

Notably, the 'interrupt' model of endings, also inferred by Linehan (1993), may be particularly helpful for individuals with a BPD diagnosis who struggle with interpersonal difficulties and perceived abandonment. However, explicitly acknowledging a model that promotes health maintenance through a cyclical process of therapy and therapeutic breaks, firstly contravenes the predominant curative model of healthcare (Fox, 1997), but also implicitly portrays a message that the therapy door is always open. Although this could help 
manage risk over time, it may unhelpfully promote dependency on services (Mann, 1973); and would be particularly problematic within the current context of service delivery (Maynard, 2017). If the interrupt model of endings were to be adopted, it would be necessary for services to have clear boundaries in place around referral criteria but also clearly defined goal-directed therapy that holds endings in mind.

\section{Strengths and Limitations}

The 'refutation' stage of analysis may be considered a notable strength of the research methodology as it aimed to ensure a balanced perspective was adopted when coding and developing themes. Deviating from the original Braun and Clarke model (2006) the additional step sought to assure 'trustworthiness' of data (Lincoln and Guba, 1985) and attempt to minimise researcher bias; strengthening the value of the qualitative research methodology.

Limitations of the research relate primarily to the representation of the sample. Firstly, the findings and recommendations were obtained from a limited sample of eight individuals who received support from four different tier-three NHS PD services. The authors acknowledge that recruitment was a challenge and that low participant numbers somewhat limits the generalisation of findings. Despite this, similar experiences were reported across the breadth of different services and therapy modalities, therefore, providing supporting evidence that the range of ending experiences are representative of general ending experiences.

A further limitation of the research relates to the assumptions regarding participants having a diagnosis of BPD, and the subsequent inferences drawn from the findings and discussion around the management of endings within this population. The authors recommend that these assumption is held in mind tentatively when interpreting the findings and considering how recommendations may be applied into clinical practice.

Another limitation is that we were unable to recruit individuals who experienced an unplanned ending. Individuals who choose to leave therapy early (an unplanned ending), do so for a variety of reasons (Bonsmann and Gubi, 2017) and, therefore, how they experience the ending may be entirely different to those who engaged with a planned ending process. Unplanned endings are considered problematic within psychotherapy practice (Swift and Callahan, 2011) and are reported to have undesirable consequences that impact service users (limited treatment gains) (Lampropoulos, 2010) and service delivery (cost implications and 
time pressures) (Barrett et al., 2008). Obtaining service users' qualitative experiences would provide a broader understanding of service users' experiences of endings that may inform intervention for preventing premature endings.

\section{Clinical and Research Recommendations}

This research contributes to the empirical research evidence base on how endings are experienced within clinical practice. The authors hope that this research initiate further rich research into the topic and that the paper stimulates further discussions amongst both researchers and health professionals on how endings are managed in clinical practice.

This study intends to inform the NICE recommendations for endings for individuals with BPD, which currently recommend that the ending of therapy is structured, phased and managed collaboratively with the individual and transitional provider. However, any extensions to the guidelines should not be seen as further prescriptions of how to end therapy but instead viewed as further points of consideration for practitioners when working on an ending with a service user. Although the study sought to inform practice with individuals receiving support from NHS community PD service, we hope that the reader will consider the subsequent recommendations as general guiding principles for managing therapy endings more effectively. Synthesised from the research findings, we recommend the following for services and health professionals:

1) Take a reflective approach to the management of endings;

2) Make endings explicit from the start;

3) Put endings on the agenda throughout therapy;

4) Plan the ending point (whether and how this will be marked);

5) Empower the ending (view the ending as the start of a new chapter);

6) Assess an individual's readiness to end and support transition throughout stages

7) As a service, support staff in managing the ending through supervision or additional training.

Interestingly, Dalzell et al., (2018) report similar recommendations for services managing treatment closures within child and adolescent services. Their findings echo that endings should be discussed upfront, planned, spoken about and supported at both an individual and staff level. Considering the similarities between the recommendations in both papers, one hypothesis is that ending experiences are similar across the lifespan; this perhaps 
might warrant the development for a more general guideline for practitioners on managing endings in practice that are not specific to diagnosis or population.

Empirical research into the management of endings is still in its infancy and, therefore, additional research should seek to understand ending experiences across a range of clinical contexts, services and perspectives (service users and staff). Further understandings would expand the current evidence base, inform existing clinical guidelines and provide evidence to support a more general guideline for ending therapy. Our findings indicate variation in how services were interpreting and delivering the current NICE guidelines; it may, therefore, be necessary to develop future research projects that invite services to share their current processes for ending. A synthesis of this information would provide a collective understanding of practice-based evidence used to inform practice. Collectively, service users' first account experiences of endings provide a qualitative understanding of how the processes of ending are experienced in clinical practice. 


\section{References}

American Psychiatric Association. (2013). Diagnostic and statistical manual of mental disorders (5th ed.), Author, Arlington, VA.

Barrett, M. S., Chua, W.J., Crits-Christoph, P., Gibbons, M. B., and Thompson, D. (2008). "Early withdrawal from mental health treatment: Implications for psychotherapy practice", Psychotherapy: Theory, Research, Practice, Training, Vol.45 No.2, pp. 247-267. doi:10.1037/0033-3204.45.2.247.

Bateman, A. W., and Fonagy, P. (2000). "Effectiveness of psychotherapeutic treatment of personality disorder", The British Journal of Psychiatry, Vol. 177 No.2, pp. 138-143. doi: 10.1192/bjp.177.2.138

Berry, K., and Haddock, G. (2008). "The implementation of the NICE guidelines for schizophrenia: Barriers to the implementation of psychological interventions and recommendations for the future", Psychology and Psychotherapy: Theory, Research and Practice, Vol. 81 No. 4, pp. 419-436. https://doi.org/10.1348/147608308X329540

Bonsmann, C., and Gubi, P. M. (2017). “Exploring clients' experiences of premature termination of counselling and psychotherapy", The Journal of Critical Psychology, Counselling and Psychotherapy, Vol. 17 No. 3, pp. 149-159. Available from: http://hdl.handle.net/10034/620874 (Accessed 14 Feb 2019)

Braun, V., and Clarke, V. (2006). "Using thematic analysis in psychology", Qualitative Research in Psychology, Vol. 3 No. 2, pp. 77-101. https://doi.org/10.1191/1478088706qp063oa

British Psychological Society (BPS) (2014). Code of Human Research Ethics, British Psychological Society, Leicester. 
Cairns, M. (2014). "Patients who come back: Clinical characteristics and service outcome for patients re-referred to an IAPT service", Counselling and Psychotherapy Research, Vol. 14 No. 1, pp. 48-55. https://doi.org/10.1080/14733145.2013.770895

Court, A. J., Cooke, A., Scrivener, A., Wells, T., and Wells, T. (2016). “They're NICE and neat, but are they useful? A grounded theory of Clinical Psychologists ' beliefs about and use of NICE guidelines", Clinical Psychology and Psychotherapy, Vol. 24 No. 4, pp. 899-910. doi: 10.1002/cpp.2054

Crabtree, B. F., and Miller, W. L (1999). Doing qualitative research. SAGE, London.

Crawford, M. J., Adedeji, T., Price, K., and Rutter, D. (2010). “Job satisfaction and burnout among staff working in community-based personality disorder services”, International Journal of Social Psychiatry, Vol. 56 No. 2, pp. 196-206. https://doi.org/10.1177\%2F0020764009105702

Crawford, M., Rutter, D., Prince, K., Weaver, T., Josson, M., Tyrer, P., ... and Moran, P. (2007). Learning the Lessons: A multi-method evaluation of dedicated communitybased services for people with Personality Disorder. National Co-ordinating Centre for NHS Service Delivery and Organisation, London. Available at: http://www.netscc.ac.uk/hsdr/files/project/SDO_FR_08-1404-083_V01.pdf (Accessed 06 June 2019).

Dalzell, K., Garland, L., Bear, H., and Wolpert, M. (2018). In search of an ending: Managing treatment closure in challenging circumstances in child mental health services. London: CAMHS Press. Available at: https://www.annafreud.org/media/6593/insearch-of-an-ending-report.pdf (Accessed 24 May 2019).

Delgado, S. V, and Strawn, J. R. (2012). "Termination of psychodynamic psychotherapy with adolescents: A review and contemporary perspective", Bulletin of the Menninger Clinic, Vol. 76 No. 1, pp. 21-52. https://doi.org/10.1521/bumc.2012.76.1.21 
Department of Health. (1998). A first class service: Quality in the new NHS. HMSO, London, UK.

Elliott, R. (2010). "Psychotherapy change process research: Realizing the promise", Psychotherapy Research, Vol. 20 No.2, pp. 123-135. https://doi.org/10.1080/10503300903470743

Etherington, K., and Bridges, N. (2011). "Narrative case study research: On endings and six session reviews", Counselling and Psychotherapy Research, Vol. 11 No. 1, pp. 1122. https://doi.org/10.1080/14733145.2011.546072

Firestein, S. K. (2001). Termination in Psychoanalysis and Psychotherapy. International University Press: Madison.

Fortune, A., Pearlingi, B., and Rochelle, C. (1992). "Reactions to Termination of Individual Treatment", Social Work, Vol. 37 No. 2, pp. 171-178. https://doi.org/10.1093/sw/37.2.171

Fox, E. (1997). "Predominance of the Curative Model of Medical Care”, JAMA, Vol. 278 No. 9, pp. 761-763. https://doi.org/10.1001/jama.1997.03550090085038

Freud, S. (1937). Analysis Terminable and Interminable. International Journal of PsychoAnalysis., Vol. 18 No. 1, pp. 373-405.

Gelso, C., and Woodhouse, H. (2002). "The termination of psychotherapy: What research tells us about the process of ending treatment", in Tyron, G. (Ed.), Counseling based on process research: Applying what we know, Allyn \& Bacon, Boston, pp. 344-369.

Holmes, J. (2010). “Termination in psychoanalytic psychotherapy: An attachment perspective", in Salberg, J. (Ed.), Good Enough Endings. Breaks, Interruptions and Terminations from Contemporary Relational Perspectives, Routledge, New-York, NY, pp. 63-82. 
Holmqvist, R., Phillips, B., and Barkham, M. (2015). "Developing practice-based evidence: benefits, challenges and tensions", Psychotherapy Research, Vol. 25 No. 1, pp. 20-31. doi: 10.1080/10503307.2013.861093

Ince, P., Haddock, G., and Tai, S. (2016). “A systematic review of the implementation of recommended psychological interventions for schizophrenia: Rates, barriers and improvement strategies", Psychology and Psychotherapy: Theory, Research and Practice, Vol. 89 No. 3, pp. 324-350. https://doi.org/10.1111/papt.12084

Keane, K., Prince, S., and Fusekova, J. (2015). "Facilitating endings and managing discharge in the Leeds Personality Disorder Service- A qualitative service evaluation." in British and Irish Study of Personality Disorder Annual Conference, $13^{\text {th }}-15$ th March, Leeds, UK.

Knox, S., Adrians, N., Everson, E., Hess, S., Hill, C., and Crook-Lyon, R. (2011). 'Clients' perspectives on the therapy termination", Psychotherapy Research, Vol. 21 No. 2, pp. 154-167. https://doi.org/10.1080/10503307.2010.534509

Korzekwa, M.I., Dell, P.F., Links., P.S., Thabane,L., and Webb, S.P. (2008) "Estimating the prevalence of borderline personality disorder in psychiatric outpatients using a two phased procedure”, Comprehensive Psychiatry, Volume 40, No 4 pp.380-386. https://do.org.uk/10.1016/j.comppsych.2008.01/007

Kubler-Ross, E. (1969). On death and dying. Macmillan, New York, NY

Kristensen, N., Nymann, C., and Konradsen, H. (2016). "Implementing research results in clinical practice- the experiences of healthcare professionals", BMC Health Services Research, Vol. 16 No.1, p.48. doi:10.1186/s12913-016-1292-y

Lampropoulos, G. K. (2010). "Type of counseling termination and trainee therapist- client agreement about change", Counselling Psychology Quarterly, Vol. 23 No. 1, 111120. doi:10.1080/09515071003721552 
Lincoln, Y., and Guba, E. (1985). Naturalistic inquiry, SAGE Publications, Newbury Park, CA.

Linehan, M. M. (1993). Diagnosis and treatment of mental disorders. Cognitive-behavioral treatment of borderline personality disorder, Guilford Press, New York, NY.

Lugtenberg, M., Zegers-Van Schaick, J. M., Westert, G. P., and Burgers, J. S. (2009). "Why don't physicians adhere to guideline recommendations in practice? An analysis of barriers among Dutch general practitioners”, Implementation Science, Vol. 4 No.1, pp. 1-9. https://doi.org/10.1186/1748-5908-4-54

Mann, J. (1973). Time-limited psychotherapy, Harvard University Press, Cambridge, MA.

Maples, J. L., and Walker, R. L. (2014). "Consolidation rather than termination: Rethinking how psychologists label and conceptualize the final phase of psychological treatment," Professional Psychology: Research and Practice, Vol. 45 No. 2, pp. 104-110. https://doi.org/10.1037/a0036250

Marx, J., and Gelso, C. (1987). "Termination of individual counseling in a university counseling center", Journal of Counseling Psychology, Vol. 34 No. 1, pp. 3-9. https://doi.org/10.1037/0022-0167.34.1.3

Maynard, A. (2017). "Shrinking the state: the fate of the NHS and social care", Journal of the Royal Society of Medicine, Vol. 110 No. 2, pp. 49-51.

https://doi.org/10.1177/0141076816686923

Mollon, P. (2009). “The NICE guidelines are misleading, unscientific and potentially impede good psychological care and help", Psychodynamic Practice, Vol. 15 No. 1, pp. 9-24. doi:10.1080/14753630802614457

National Institute of Health and Care Excellence (NICE). (2009). Borderline Personality Disorder: Treatment, Management and Prevention. The British Psychological Society and the Royal College of Psychiatrists, Leicester and London (UK). 
National Institute of Mental Health in England [NIMHE]. (2003). Breaking the cycle of rejection: The personality disorder capabilities framework. Available from: http://personalitydisorder.org.uk/wp-content/uploads/2015/06/personalitydisorderscapabilities-framework.pdf (Accessed 11 May 2019).

Norona, J. C., Olmstead, S. B., and Welsh, D. P. (2016). “Breaking Up in Emerging Adulthood: A Developmental Perspective of Relationship Dissolution”, Emerging Adulthood, Vol. 5 No. 2, pp. 116-127. https://doi.org/10.1177/2167696816658585

Olivera, J., Braun, M., Penedo, J. M. G., and Roussos, A. (2013). “A qualitative investigation of former clients' perception of change, reasons for consultation, therapeutic relationship and termination", Psychotherapy, Vol.50 No. 4, pp. 505-516. https://doi.org/10.1037/a0033359

Prochaska, J. O., and DiClemente, C. C. (1983). "Stages and processes of self-change of smoking: Toward an integrative model of change", Journal of Consulting and Clinical Psychology, Vol. 51 No 3, pp. 390-395. https://doi.org/10.1037/0022-006X.51.3.390

Prochaska, J., Norcross, J., and Diclemente, C. (2013). "Applying the Stages of Change”, Psychotherapy in Australia, Vol.19 No. 2, pp. 10-15. https://doi.org/10.1093/med:psych/9780199845491.003.0034

Prytys, M., Garety, P. A., Jolley, S., Onwumere, J., and Craig, T. (2011). "Implementing the NICE guideline for schizophrenia recommendations for psychological therapies: a qualitative analysis of the attitudes of CMHT staff', Clinical Psychology and Psychotherapy, Vol. 18 No. 1, pp. 48-59. https://doi.org/10.1002/cpp.691 Quintana, S. M. (1993). “Toward an Expanded and Updated Conceptualization of Termination: Implications for Short-Term, Individual Psychotherapy”, Professional Psychology: Research and Practice, Vol. 24 No.4, pp. 426-432. https://doi.org/10.1037/0735-7028.24.4.426 
Quintana, S. M., and Holahan, W. (1992). “Termination in Short-Term Counselling: Comparison of Successful and Unsuccessful Cases", Journal of Counselling Psychology, Vol. 39 No. 3, pp. 299-305.

Råbu, M., Binder, P. E., and Haavind, H. (2013). "Negotiating ending: A qualitative study of the process of ending psychotherapy", European Journal of Psychotherapy and Counselling, Vol. 15 No. 3, pp. 274-295. https://doi.org/10.1080/13642537.2013.810962

Roe, D., Dekel, R., Harel, G., and Fennig, S. (2006). “Clients' reasons for terminating psychotherapy: A quantitative and qualitative inquiry", Psychology and Psychotherapy: Theory, Research and Practice, Vol. 79 No. 4, pp. 529-538. https://doi.org/10.1348/147608305X90412

Sheehy, G. (1977). Passages, predictable crisis of adult life. (B. Books, Ed.). Bantam, New York, NY.

Sroufe, L. A. (2005). “Attachment and development: A prospective, longitudinal study from birth to adulthood", Attachment and Human Development, Vol. 7 No. 4 pp. 349-367. https://doi.org/10.1080/14616730500365928

Strupp, H. H., and Binder, J. L. (1984). Psychotherapy in a new key: A guide to time-limited dynamic psychotherapy, Basic Books, New York, NY.

Swift, J. K., and Callahan, J. L. (2011). "Decreasing treatment dropout by addressing expectations for treatment length", Psychotherapy Research, Vol. 21 No. 2, pp. 193200. doi:10.1080/10503307.2010.541294

Wachtel, P. (2002). "Termination of therapy: An effort at integration", Journal of Psychotherapy Integration, Vol. 12 No. 3, pp. 373-383. https://doi.org/10.1037/10530479.12.3.373 
Webb, K., Schroder, T.A., and Gresswell, D. M. (2018). 'Service users' first accounts of experiencing endings from a psychological service or therapy: A systematic review and meta-ethnographic synthesis", Psychology and Psychotherapy, Theory, Research and Practice, Vol 92, No. 4, pp 584-604. doi: 10.1111/papt.12201.

Webb, K. (2009). Service users' experiences of endings from NHS community personality disorder services. University of Lincoln Repository. Available from: http://eprints.lincoln.ac.uk/id/eprint/39304/1/RPV\%201819\%204263873\%2015591685 \%20Research\%20Project\%20Portfolio\%20Volume\%201_.pdf

Westamacott, R., and Hunsley, J. (2017). "Psychologists' perspectives on therapy termination and the use of therapy engagement/retention strategies", Clinical Psychology and Psychotherapy, Vol. 24 No. 3, pp. 687-696. doi: 10.1002/cpp.2037

Wood, H., Bolton, W., Lovell, K., and Morgan, L. (2014). Meeting the challenge, making a difference: Working effectively to support people with personality disorder in the community. Project Report. Department of Health, London. Available from: http://repository.tavistockandportman.ac.uk/864/1/Heather_Wood__MeetingTheChallenge.pdf (Accessed 03 March 2019).

Young, J., Klosko, J., and Weishaar, M. (2003). Schema therapy: a practitioners guide. Guilford Press, New York, NY. 
